\title{
New LASER Design for NIR LidAR Applications
}

\author{
H. Vogelmann ${ }^{1}$, T. Trickl ${ }^{1}$, M . Perfahl ${ }^{1}$, S. Biggel ${ }^{2}$ \\ ${ }^{1}$ Karlsruhe Institute of Technology, IMK-IFU (Garmisch-Partenkirchen,Germany),, E-mail: \\ hannes.vogelmann@kit.edu \\ ${ }^{2}$ Optic Instiute Ulm, Germany
}

\begin{abstract}
Recently, we quantified the very high spatio-temporal short term variability of tropospheric water vapor in a three dimensional study [1]. From a technical point of view this also depicted the general requirement of short integration times for recording water-vapor profiles with lidar. For this purpose, the only suitable technique is the differential absorption lidar (DIAL) working in the near-infrared (NIR) spectral region. The laser emission of most water vapor DIAL systems is generated by Ti:sapphire or alexandrite lasers. The water vapor absorption band at $817 \mathrm{~nm}$ is predominated for the use of Ti:sapphire. We present a new concept of transversely pumping in a Ti:Sapphire amplification stage as well as a compact laser design for the generation of single mode NIR pulses with two different DIAL wavelengths inside a single resonator. This laser concept allows for high output power due to repetitions rates up to $100 \mathrm{~Hz}$ or even more. It is, because of its compactness, also suitable for mobile applications.
\end{abstract}

\section{INSTRUMENTS AND REQUIREMENTS}

\subsection{The Zugspitze DIAL}

Our water vapor DIAL system is located just below Mt. Zugspitze $\left(47.42^{\circ} \mathrm{N}, 10.98^{\circ} \mathrm{E}, 2962 \mathrm{~m}\right.$ a.s.l.) which is by far the highest mountain on the northern rim of the Alps. The free troposphere above this site is representative of Central Europe. The mountain top is above the moist boundary layer for most of the year. Due to reduced absorption losses this site is ideal for sensitive spectroscopic measurements of water vapor throughout the free troposphere. Single absorption lines in the 817-nm band of $\mathrm{H}_{2} \mathrm{O}$ are used for ground-based water vapor profiling in a vertical range from $2.95 \mathrm{~km}$ to roughly $12 \mathrm{~km}$ a.s.l.. Statistical measurement uncertainties are kept below about $5 \%$ to about $8 \mathrm{~km}$ by dynamically adapting the vertical resolution. The sensitivity limit is roughly $18 \mathrm{ppm}$ at $10 \mathrm{~km}$ a.s.l. [2]. This DIAL system and the retrieval of water vapor profiles are described in more detail in [3]. Water-vapor profiles from the Zugspitze DIAL allow for retrieving IWV with a precision better than $0.1 \mathrm{~mm}$ [4]. For a suitable signal-to-noise ratio $10^{4}$ laser shots of about $100 \mathrm{~mJ}$ have to be integrated each wavelength. At a repetition rate of $20 \mathrm{~Hz}$ of the current laser system, this takes almost 17 minutes overall. Our investigations [1] have shown, that an integration time of less than 5 minutes is desirable.

\subsection{The mobile ATMONSYS lidar}

Since 2012, a mobile scanning lidar for profiling watervapor, aerosol and temperature in the planetary boundary layer (PBL) has been developed at IMK-IFU with in the ATMONSYS project. The new system will be used in field campaigns and can be transported to sites of special interest. Thus, the lidar is housed in a 20 feet shipping container and can easily be moved with a standard truck.

With respect to the high short-term variability in the PBL and the requirement of analyzing atmospheric short-term dynamics one major goal was to provide short integration times of the order of $10 \mathrm{~s}$. Thus, a high repetition rate of $100 \mathrm{~Hz}$ and an infrared pulse energy of at least $50 \mathrm{~mJ}$ was aimed at $817 \mathrm{~nm}$. Additional requirements for the ATMONSYS lidar system are robustness due to being transported on rough roads, compactness, and low power consumption due to the lack of high-power current at measurement sites somewhere in the hinterland.

\subsection{Laser amplifier}

Water-vapor measurements throughout the troposphere with the DIAL method require narrow-band laser emission with high spectral purity and high pulse energy. A high pulse energy is, in particular, essential during daytime since the lidar signal must be substantially larger than the solar background. Due to its advantageous wavelength range, covering the three important band systems of water-vapor around $725 \mathrm{~nm}, 817 \mathrm{~nm}$ and $935 \mathrm{~nm}$, Ti:sapphire is ideal for humidity sounding and has, thus, been used as the laser medium in several successfully applied DIAL systems [5-9]. The design goal had been to provide widely tunable NIR radiation approaching the pulse-energy level of conventional fixed-frequency lasers of the order of $1 \mathrm{~J}$. This could be achieved by directly pumping Ti:sapphire with flashlamps and this was our approach for the construction of Zugspitze DIAL [3]. Here, we could extract single-mode laser pulses with energies up to $250 \mathrm{~mJ}$ from an amplifier ring at a repetition rate of $20 \mathrm{~Hz}$. This limitation was due to arcing inside the power supply above flashlamp load voltages of $26 \mathrm{kV}$. Increasing the average power by a higher repetition rate was limited by the performance of the power supply $(\approx 10 \mathrm{~kW})$. For a safely routine operation we used a pulse energy of less than $150 \mathrm{~mJ}$. After 11 years of lidar operation the power supply suffered a major damage without a chance of reparation or replacement. A new concept of laser amplification had to be found. A second motivation for the development of a new high power Ti:Sapphire laser amplifier was the construction of the mobile ATMONSYS 
lidar. A key requirement for quantitative DIAL sounding of water vapor is the spectral purity of the laser system [10]. The spectral purity of at least $99.9 \%$ was determined for the flashlamp pumped system and we expect the same for the transversely laser pumped setup.

Ordinary Ti:sapphire amplifiers work in a traveling wave configuration with multiple passes through a rod pumped longitudinally with a laser at $532 \mathrm{~nm}$. Pumping Ti:sapphire longitudinally limits the length of the rod to the depth of penetration of the pump light which is typically about $10 \mathrm{~mm}$ at $532 \mathrm{~nm}$. If pumped bidirectionally, a length of $20 \mathrm{~mm}$ is useful. Thus, it is not possible to increase the stored energy just by using a longer rod. In terms of single shots, this could partly be solved by enlarging the diameter of the rod and by enlarging the pump energy up to the limit of the damage threshold. In terms of average output power, this is also limited by thermal effects, because the cooling cylinder barrel grows only linear with the diameter of the rod, while the fluorescent area grows quadratically. With the introduction of diode pumped Nd:YAG lasers, pump sources with a moderate and appropriate pulse energy $(100 \mathrm{~mJ}-400 \mathrm{~mJ})$, but with high repetition rates $(100 \mathrm{~Hz}$ and more), have become available. The average output of such lasers is too much for conventional longitudinal pumping of $20-\mathrm{mm}$ long Ti:sapphire rods.

Experienced in transversely flashlamp pumping a Ti:Sapphire with an average pump power of more than $2 \mathrm{~kW}$ we started the promising development of a transversely laser pumped Ti:Sapphire amplifier stage. Transversely pumping allows for the use of a longer rod, because the penetration depth of the pump light does not limit its length. This yields the advantage of a much better ratio of cooled surface and fluorescent volume. Disadvantageous, on the other hand, are geometrical limitations in terms of a multi pass traveling wave arrangement with a geometrical setup as a dragonfly, because the ratio of aperture and length of the rod is much smaller than for longitudinally pumped rods. Thus, for high power applications, a long transversely pumped rod must be part of a traveling wave resonator with only one optical path. A principle setup is shown in Fig. 1.

The initially weak laser pulses from the oscillator are amplified in alternating sequence in the Ti:sapphire ring amplifier similar to the design by A. Kung [11]. The linearly polarized pulses enter the ring cavity where they are stored for amplification due to a rotation of the beam polarization by 90 degrees by a prism combination. After the first round trip the Pockels cell is switched on to counteract this rotation until the maximum amplification is reached after several round trips. After switching off the Pockels cell the amplified pulse is released. Therefore, the high voltage $(6 \mathrm{kV})$ for the Pockels cell must be switched both on and off in a time significantly shorter than the circulation time of the laser pulses (e.g. $16 \mathrm{~ns}$ at a ring circumference of $4.8 \mathrm{~m}$ ). We developed a pulse generator with both rise and fall times of $6 \mathrm{~ns}$ as well as a constant voltage level during the storage period.

\subsection{Laser oscillators}

The two DIAL wavelengths $\lambda_{\text {on }}$ and $\lambda_{\text {off }}$ of the Zugspitze DIAL are generated with two SLM optical parametric oscillators (OPO), which are based on a Littman cavity and a KTP (potassium titanyl phosphate) crystal as the OPO medium ([12]). This type of OPO provides a very wide tuning range from less than $700 \mathrm{~nm}$ to more than $1 \mu \mathrm{m}$ with a rather constant output of about $0.5 \mathrm{~mJ}$ and is, therefore, highly suitable as the master oscillator for a tunable infrared laser system. The OPOs have been simultaneously pumped (10mJ each, $532 \mathrm{~nm}$ ) by one common flashlamp-pumped injection-seeded and frequencydoubled Nd:YAG laser. The repetition rate of $20 \mathrm{~Hz}$ was adequate to the flashlamp pumped Ti:sapphire laser amplifier. By experiment, we showed, that a stable SLM operation is also possible at $100 \mathrm{~Hz}$. After some improvements [3] we reduced the frequency noise of the OPOs from $\pm 140 \mathrm{MHz}$ to $\pm 35 \mathrm{MHz}$ and achieved a single-shot SLM emission of the OPOs almost at the Fourier-transform limit. A single shot bandwidth of $130 \pm 15 \mathrm{MHz}$ (4 ns) was measured. The lidar measurements have so far been carried out with the normal OPO pulse length of $2.0 \mathrm{~ns}$ resulting in an approximately doubled bandwidth. This is narrow enough to avoid errors by spectral contributions outside the absorption line center [9], considering the typical line widths of tropospheric water vapor between $2 \mathrm{GHz}$ and $4 \mathrm{GHz}$.

In the ATMONSYS lidar, the two DIAL wavelength are generated with two tunable diode lasers $(\mathrm{cw})$. The initial laser pulses are formed in a ring resonator following K. Ertel [8] with a longitudinal bidirectionally pumped Ti:sapphire rod with Brewster cut. This technique allows for a much more compact arrangement and provides much more mechanical stability due to the requirements of a mobile system. The laser pulses are generated by coupling the continuous emission from the diode lasers into the resonator in alternating sequence synchronously to the pump laser. A major challenge was the development of the electronics controlling the resonator in a way that both wavelength are resonant in alternating sequence while synchronized with the pump laser $(100 \mathrm{~Hz})$. The approach of Ertel et al. [8] using a backward and resonant signal processed by a personal computer was discarded because of being too slow for the operation with $100 \mathrm{~Hz}$. Thus, we decided to use analog computers for controlling the resonator. Its length is modulated with a sine at a frequency of $200 \mathrm{~Hz}$ synchronized with the pump laser and with an amplitude covering at least two modes. Sampleand-hold circuits record the resonant mirror positions of both wavelengths while the pump laser is off in order to avoid a distortion by the pump light. By phase shifting the modulating sine, the two resonant mirror positions are tuned exactly to the time of the next pump pulse presuming that there is no significant drift of the two laser wavelengths during the period of about $5 \mathrm{~ms}$. The stabilization of the mirror positions is achieved with a PID controller for each wavelength. The wavelengths the diode lasers are controlled with a WS 7 lambda meter (High Finesse). 


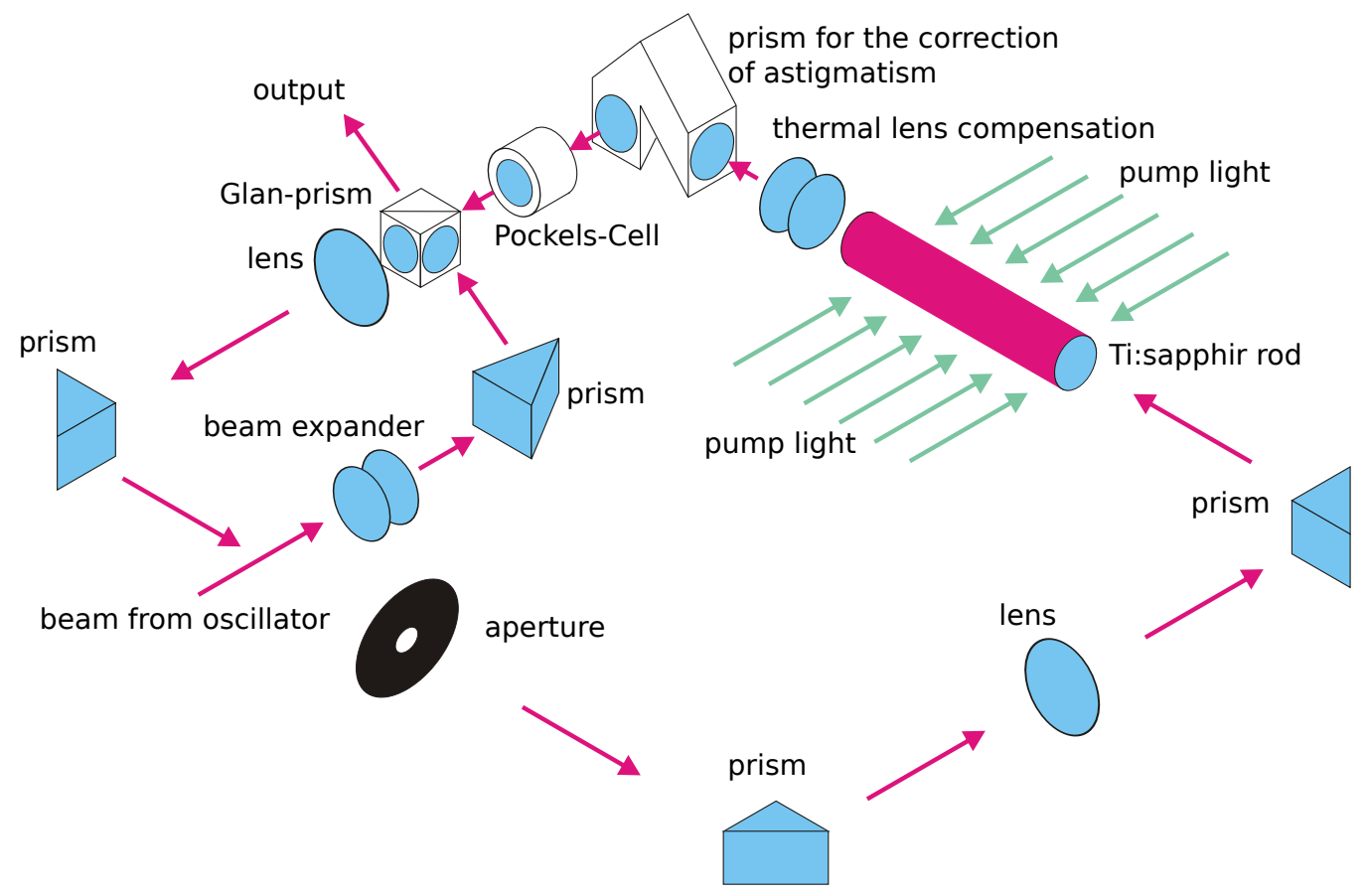

Figure 1: Fundamental design of a traveling wave amplifier stage which is based on a ring resonator and suitable for a long transversely pumped Ti:sapphire rod. Because of the ring design, nanosecond pulses must actively be coupled in and out with a Pockels cell and a polarizing beam splitter. The two single lenses with the aperture in their focus work as spatial filter and as relays optic imaging the rod into itself. The thermal lensing of the Ti:sapphire rod is compensated by a concave-convex lens combination that is adjusted also for a conservation of the beam diameter. A major issue is the astigmatism of the thermal lens which causes problems with the beam quality without adequate compensation. A special combination of prisms in the upper corner solves this problem by rotating the beam by $90^{\circ}$ around its axis. In this way the astigmatic distortion is self-corrected each round trip. This prism combination also rotates the polarisation about $90^{\circ}$, which is needed for the coupling operation with the Pockels cell.

\section{FIRST RESULTS OF TRANSVERSELY PUMP- ING TI:SAPPHIRE WITH A LASER}

For experiments with transversely pumping we purchased several cylindrical Ti:sapphire rods $(\varnothing 10 \mathrm{~mm})$ with different lengths $(50 \mathrm{~mm}, 100 \mathrm{~mm}, 150 \mathrm{~mm})$ and different doping levels $(0.7 \%$ and $0.1 \%)$.

In a very preliminary attempt we pumped a cylindrical $150 \mathrm{~mm}$ rod $(\varnothing 10 \mathrm{~mm})$ in a Fabry-Pérot resonator with $300 \mathrm{~mJ}(532 \mathrm{~nm})$ from one side and extracted $7 \mathrm{~mJ}$. Obviously, only a small fraction of the volume of the rod was pumped because the cylindrical barrel focussed the pump light to a narrow area at the opposite side. According to our former system pumped with four flashlamps, we tried to pump the rod in a Bethune arrangement [13] in 4 directions. This increased the pumped volume significantly, but, no laser emission was possible, even with a short rod of $50 \mathrm{~mm}$. We concluded, that the polarisation of the pump light was not optimal because of the orientation of the c-axis of the Ti:sapphire crystal. Thus, the contribution to the laser gain was quite small for two transverse pumping directions, although the visible fluorescence seemed to be rather homogeneous across the rod (Fig. 2). In a next step we pumped the rod transversely from two opposite sides with an optimal orientation of the c-axis. Now we could extract $23 \mathrm{~mJ}$ from a Fabry-Pérot resonator and a cross-section of $25 \mathrm{~mm}^{2}$. Nanosecond laser pulses from our OPOs could be amplified in a single pass with a gain of about 1.5 to 2 .

\section{OUTLOOK AND CONCLUSIONS}

The next step will be the use of a rod with flat side walls. This should allow for a more homogeneous illumination of its volume. The rod is still in fabrication. For the operational use with high average power the rod needs to be cooled in a water floated bulb. By experiment we found that placing the rod in a water-filled glass tube slightly enhances the pump efficiency because of a better index matching. The results are rather promising. If pumping the entire cross-ection of $78 \mathrm{~mm}^{2}$ with the same intensity one could expect a pulse energy of about $70 \mathrm{~mJ}$ from a $50 \mathrm{~mm}$-rod and even more than $200 \mathrm{~mJ}$ from $150 \mathrm{~mm}$ rod. A repetition rate of $100 \mathrm{~Hz}$ could perform an avarage power of about $7 \mathrm{~W}$ or even more than $20 \mathrm{~W}$, respectively. For extracting $20 \mathrm{~W}$, pumping with at least $100 \mathrm{~W}$ $(532 \mathrm{~nm})$ will be required, which is not available in our case. However, the method of transversely pumping has this great potential, and $100 \mathrm{~W}$ is still far from cooling 


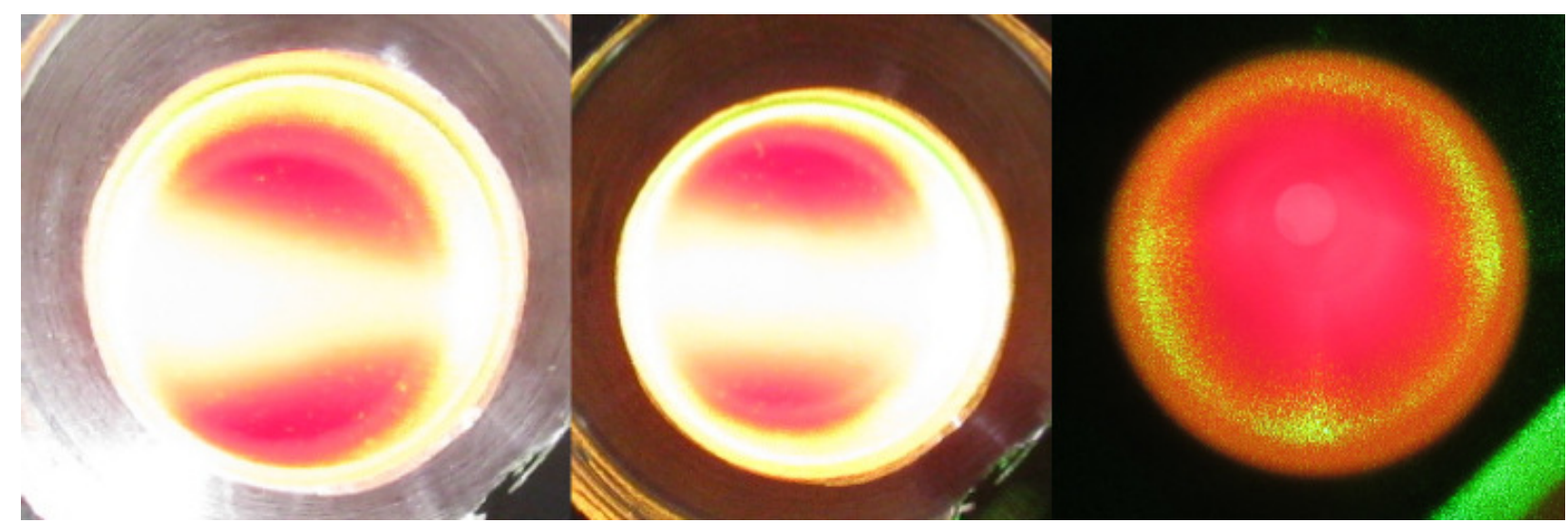

Figure 2: Fluorescence of three different pumping configurations. Left: Single sided pumping from left. Middle: Two sided pumping from left and right. Right: Four sided pumping in a Bethune setup.

limits if the rod is directly cooled by water. For narrowband lidar-soundings in the NIR this could contribute a significant progress, in particular for fast scanning applications or for observing short-term atmospheric processes.

\section{ACKNOWLEDGMENTS}

We thank Hans-Peter Schmid (KIT/IMK-IFU) for his continual interest in this work. We also acknowledge the funding by the German Federal Ministry of Economy within the program ZIM (Zentrale Innovation Mittelstand) and the assistance of our project partner Radiant Dyes Laser \& Accessoires GmbH.

\section{REFERENCES}

1. Vogelmann, H., Sussmann, R., Trickl, T., and Reichert, A. Spatiotemporal variability of water vapor investigated using lidar and ftir vertical soundings above the zugspitze. Atmos. Chem. Phys., 15:31353148, 2015.

2. Trickl, T., Vogelmann, H., Fix, A., Schäfler, A., Wirth, M., Calpini, B., Levrat, G., Romanens, G., Apituley, A., Wilson, K. M., Begbie, R., Reichardt, J., Vömel, H., and Sprenger, M. How stratospheric are deep stratospheric intrusions? LUAMI 2008. Atmospheric Chemistry and Physics, 16(14):87918815, 2016.

3. Vogelmann, H. and Trickl, T. Wide Range Sounding of Free Tropospheric Water Vapor with a Differential Absorption Lidar (DIAL) at a High Altitude Station. Appl. Opt., 47(12):2116-2132, 2008.

4. Vogelmann, H., Sussmann, R., Trickl, T., and Borsdorff, T. Intercomparison of atmospheric water vapor soundings from the differential absorption lidar (DIAL) and the solar FTIR system on Mt. Zugspitze. Atmos. Meas. Tech., 4(5):835-841, 2011.

5. Moore, A. S., Brown, K. E., Hall, W. M., Barnes, J. C., Edwards, W. C., Petway, L. B., Little, A. D., Luck, W. S., Jones, I. W., Antill, C. W., Browell,
E. V., and Ismail, S. Development of the lidar atmospheric sensing experiment (lase) - an advanced airborne dial instrument. In A. Ansmann, R. Neuber, P. R. and Wandinger, U., editors, Advances in Atmospheric Remote Sensing with Lidar, pages 281288. Springer-Verlag, 1996. Selected Papers of the 18th International Laser Radar Conference (ILRC), Berlin, 22-26 July 1996.

6. Browell, E. V., Ismail, S., and Grant, W. B. Differential absorption lidar (DIAL) measurements from air and space. Appl. Phys. B, B 67:399-410, 1998.

7. Nagasawa, C., Nagai, T., Abo, M., Shibata, Y., and Uchino, O. Developement of airborne dial for water vapor measurement. In Singh, U. N., Itabe, T., and Sugimoto, N., editors, Lidar Remote Sensing for Industry and Environment Monitoring - Proceedings of SPIE - The International Society for Optical Engineering, volume 4153, pages 599-606. 2001.

8. Ertel, K., Linné, H., and Bösenberg, J. Injectionseeded pulsed ti:sapphire laser with novel stabilization scheme and capability of dual-wavelength operation. Appl. Opt., 44:5120-5126, August 2005.

9. Wulfmeyer, V. Ground-based differential absorption lidar for water-vapor temperatur-profiling: development and specifications of a high-performance laser transmitter. Appl. Opt., 37(18):3804-3824, 1998.

10. Bösenberg, J. Ground-based differential absorption lidar for water-vapor and temperature profiling: methodology. Appl. Opt., 37(18):3845-3860, 1998.

11. Kung, A. H. Regenerative amplification of a singlefrequency optical parametric oscillator. Opt. Lett., 18(23):2017 - 2019, April 1993.

12. Bosenberg, W. R. and Guyer, D. R. Broadly tunable, single-frequency optical parametric freqencyconversion system. J. Opt. Soc. Am. B, 10(9):17161722, 1993.

13. Bethune, D. S. Dye cell design for high-power lowdivergence excimer-pumped dye lasers. Appl. Opt., 20:1897-1899, June 1981. 